\title{
The Role of N-Acetyltransferase 2 Polymorphism in the Etiopathogenesis of Inflammatory Bowel Disease
}

\author{
M. Baranska $\cdot$ R. Trzcinski $\cdot$ A. Dziki $\cdot$ \\ M. Rychlik-Sych $\cdot$ M. Dudarewicz • \\ J. Skretkowicz
}

Received: 8 August 2010/Accepted: 9 December 2010/Published online: 15 February 2011

(C) The Author(s) 2011. This article is published with open access at Springerlink.com

\begin{abstract}
Background and Purpose Inflammatory bowel disease (IBD) consists of ulcerative colitis (UC) and Crohn's disease $(\mathrm{CD})$, which are complex genetic disorders resulting from the interplay between several genetic and environmental risk factors. The arylamine $\mathrm{N}$-acetyltransferase 2 (NAT2) enzyme detoxifies a wide spectrum of naturally occurring xenobiotics including carcinogens and drugs. Acetylation catalyzed by NAT2 is an important process in metabolic activation of arylamines to electrophilic intermediates that initiate carcinogenesis. The aim of our study was to determine whether there is any association between the susceptibility to inflammatory bowel disease among the variations of NAT2 genotypes.

Methods This study was carried out in 80 patients with IBD. The control group consisted of 100 healthy volunteers. The most common mutations found in the Caucasian population are at the positions $481 \mathrm{~T}, 803 \mathrm{G}, 590 \mathrm{~A}$ and $857 \mathrm{~A}$ on the NAT2 gene. This was determined using the polymerase chain reaction-restriction fragment length polymorphism method with DNA extracted from peripheral blood.

Results Risk of IBD development was 3.86 for the carriers of the $N A T 2 * 5 / N A T 2 * 7$ genotype and 2.53 for the carriers with $N A T 2 * 6 / N A T 2 * 7$, but it was not statistically
\end{abstract}

M. Baranska · M. Rychlik-Sych · M. Dudarewicz ·

J. Skretkowicz

Department of Pharmacogenetics, Medical University of Lodz,

Muszynskiego 1, 90-151 Lodz, Poland

R. Trzcinski $(\square) \cdot$ A. Dziki

Department of General and Colorectal Surgery,

Medical University of Lodz, Plac Hallera 1,

90-647 Lodz, Poland

e-mail: trzcinskir@wp.pl significant. A statistically significant correlation between the $N A T 2 * 7$ allele prevalence and the risk for developing IBD was found (OR $=5.8 ; P=0.005)$.

Conclusions Higher prevalence of the NAT2*7 allele in patients with IBD and the obtained OR values could suggest that this mutation has the effect of increasing IBD development. Future studies are needed to confirm our assumptions on larger group of patients.

Keywords Inflammatory bowel disease $\cdot$ NAT2 $\cdot$ Genetic polymorphism

\section{Introduction}

Inflammatory bowel disease (IBD) is a term encompassing a group of chronic inflammatory diseases of unknown etiology which affect the gastrointestinal tract. They include Crohn's disease (CD) and ulcerative colitis (UC) [1]. Both diseases are considered non-specific since their causative factors remain unknown. Genetic, immunologic, bacterial, environmental, and psychological factors are believed to be factors in the pathogenesis [2]. The role of genetic factors is supported by race/ethnic difference, e.g. IBD occurs with higher frequency in the Caucasian race [3]. Higher morbidity was observed when it occurred within the same families, especially in the first-degree relatives (30-100 times higher) and in the monozygotic twins [4]. In the studies on the genetic basis of inflammatory bowel disease, HLA class II encoding genes and their relationship with some regions of chromosomes 1, 5, 6, 12, 14, 16, 19 are also considered [4,5]. Taking into account that both genetic and environmental factors play a role in the pathogenesis of inflammatory bowel disease, it would be interesting to determine if there is any relation between 
genetically determined activity of the xenobiotic metabolizing enzymes and morbidity of IBD.

$\mathrm{N}$-acetyltransferase 2 (NAT2) is a II-phase biotransformation enzyme responsible for detoxification of xenobiotics which have the structure of aromatic amines, hydrazine, sulphonamides and aliphatic amines. NAT 2 takes part in the acetyl group transfer from the co-enzyme A to the hydrophobic substrates, increasing their solubility. Carcinogenic and mutagenic compounds may be produced as a result of these reactions. Arylamines and hydrazines, frequently occurring in the environment, may contribute to the pathogenesis of numerous diseases [6-8].

NAT2 activity is genetically determined and is dependent on patient's genotype resulting from the presence of two alleles in the NAT2 gene, which is localized on chromosome 8 where various point mutations may occur. A regularly updated list of NAT2 gene alleles is presented by the University of Louisville on their website: http://louisville. edu/medschool/pharmacology web page [9]. A majority of the mutated alleles of NAT2 encode a protein of the reduced enzymatic activity [10-12].

The acetylation genotype is believed to predispose a patient to numerous diseases. The role of NAT2 polymorphism was investigated in prostate cancer, gastrointestinal tract cancer, urinary bladder cancer, systemic lupus erythematosus (SLE), endometriosis, Parkinson's and Alzheimer's disease [13-18]. However, there are few reports on the influence of the acetylation genotype on the morbidity of IBD. Our study is the first that estimates the distribution of NAT2 genotypes in patients suffering from inflammatory bowel disease in Poland. A study of the NAT2 genotype may broaden our knowledge of the genetic etiology and pathogenesis of IBD, and provide important data, which may be useful in the diagnostics and treatment of IBD.

\section{Patients and Methods}

Eighty patients with inflammatory bowel disease, treated at the Department of General and Colorectal Surgery of the Medical University of Lodz, were included in the study. A total of 80 patients (50 males and 30 females) with inflammatory bowel disease were analyzed. The median age of patients was $42.7 \pm 14.6$ years (range 19-74 years). In 53 patients, ulcerative colitis (UC) was diagnosed and 27 patients fulfilled the criteria for Crohn's disease (CD). The control group included 100 healthy volunteers -41 males and 59 females, aged 18-90 (median age, 52.5 \pm 20.1 years). The study was approved by the local ethics committee on human research, and informed consent was obtained from all patients.

Genomic DNA was isolated from the leukocytes extracted from the peripheral blood according to
Gustincich's method [19]. NAT2 genotype identification was performed according to the Spurr's method [20]. Genomic DNA was subjected to amplification using PCR (polymerase chain reaction) and subsequently the obtained product was subjected to digestion by restriction enzymes (RFLP method-restriction fragment length polymorphism) in order to detect mutated alleles of the NAT2 gene, responsible for slow acetylation. Kpn1 and Dde1 enzymes recognized $N A T 2 * 5$ allele, Taq $1-N A T 2 * 6$, allele and BamH1-NAT2*7 allele. Lack of restriction sites for a particular endonuclease suggested presence of a wild-type allele $N A T 2 * 4$. Separation of the obtained digestion products was performed by electrophoresis in $8 \%$ polyacrylamide gel. The obtained bands corresponding with particular DNA fragments were stained with ethidium bromide and subsequently analyzed under ultraviolet light. Having discovered alleles of the following genes of NAT2: $N A T 2 * 4, N A T 2 * 5, N A T 2 * 6$, and $N A T 2 * 7$, specific genotypes responsible for slow and fast acetylation phenotypes were determined. $N A T 2 * 4 / N A T 2 * 4, N A T 2 * 4 / N A T 2 * 5$, $N A T 2 * 4 / N A T 2 * 6$ and $N A T 2 * 4 / N A T 2 * 7$ genotypes determine fast acetylation phenotypes, while $N A T 2 * 5 / N A T 2 * 5$, $N A T 2 * 5 / N A T 2 * 6, \quad N A T 2 * 5 / N A T 2 * 7, \quad N A T 2 * 6 / N A T 2 * 6$, $N A T 2 * 6 / N A T 2 * 7$ and $N A T 2 * 7 / N A T 2 * 7$ genotypes are responsible for slow acetylation phenotypes.

The obtained results were subjected to the statistical analysis. Any statistically important difference in the incidence of the NAT2 genotypes in the group of patients with inflammatory bowel disease and in the control group was calculated using $\chi^{2}$. Relative risk of the disease occurrence was assessed using odds ratio (OR) with an appropriate confidence interval (CI). Statistical analysis was performed using the computer program Statistica 6.0.

\section{Results}

In the group of patients with inflammatory bowel disease, the majority of them were characterized by a genotype that resulted in the slow acetylation of xenobiotics (55\%). Subjects with fast acetylation genotype constituted only $45 \%$ of the group. No statistically significant difference was observed in the incidence of particular NAT2 genotypes between the group of patients with inflammatory bowel disease and the control group (Table 1).

Different $\mathrm{N}$-acetyltransferase 2 genotypes in both groups of patients are shown in Table 2. NAT2*4/NAT2*5 $(21.3 \%)$ and $N A T 2 * 5 / N A T 2 * 6(20 \%)$ genotypes were prevalent in the IBD group, while NAT2*4/NAT2*6 (30\%) and $N A T 2 * 5 / N A T 2 * 6(25 \%)$ genotypes were most frequent in the control group. No statistical difference in the incidence of specific NAT2 genotypes was observed in the group of subjects with IBD and in the control group. Relative risk of 
Table 1 Distribution of genotypes determining slow and fast acetylation in patients with IBD and in controls

\begin{tabular}{|c|c|c|c|c|c|c|c|c|c|c|}
\hline \multirow[t]{2}{*}{ Acetylation genotype } & \multirow{2}{*}{$\begin{array}{l}\text { Control group }(N=100) \\
n(\%)\end{array}$} & \multicolumn{3}{|c|}{ IBD $(N=80)$} & \multicolumn{3}{|c|}{$\mathrm{UC}(N=53)$} & \multicolumn{3}{|c|}{$\mathrm{CD}(N=27)$} \\
\hline & & $n(\%)$ & $\chi^{2}$ & $P$ & $n(\%)$ & $\chi^{2}$ & $P$ & $n(\%)$ & $\chi^{2}$ & $P$ \\
\hline Slow acetylators & $53(53 \%)$ & $44(55 \%)$ & 0.07 & 0.791 & $29(54.7 \%)$ & 0.04 & 0.839 & $15(55.6 \%)$ & 0.06 & 0.806 \\
\hline Fast acetylators & $47(47 \%)$ & $36(45 \%)$ & & & $24(45.3 \%)$ & & & $12(44.4 \%)$ & & \\
\hline
\end{tabular}

$I B D$ inflammatory bowel disease, $U C$ ulcerative colitis, $C D$ Crohn's disease

$P$ significantly lower $(P<0.01)$

$\chi^{2} \mathrm{Chi}^{2}$ test comparing two groups

Table 2 Frequency distributions of NAT2 genotypes in the group of patients with IBD and in the controls

$I B D$ inflammatory bowel disease, $O R$ odds ratio, $95 \% C I$ 95\% confidence interval

$P$ significantly lower $(P<0.01)$

\begin{tabular}{|c|c|c|c|c|c|c|}
\hline \multirow[t]{2}{*}{ NAT2 genotype } & \multicolumn{2}{|c|}{ Patients with IBD, $N=80$} & \multicolumn{2}{|c|}{ Controls, $N=100$} & \multirow[t]{2}{*}{$P$} & \multirow[t]{2}{*}{ OR $(95 \% \mathrm{CI})$} \\
\hline & $n$ & $\%$ & $n$ & $\%$ & & \\
\hline \multicolumn{7}{|l|}{ Fast acetylator } \\
\hline \multicolumn{7}{|l|}{ Homozygous } \\
\hline$N A T 2 * 4 / N A T 2 * 4$ & 7 & 8.8 & 4 & 4 & 0.647 & $1.65(0.465-5.847)$ \\
\hline \multicolumn{7}{|l|}{ Heterozygous } \\
\hline$N A T 2 * 4 / N A T 2 * 5$ & 17 & 21.3 & 12 & 12 & 0.094 & $1.98(0.717-5.463)$ \\
\hline$N A T 2 * 4 / N A T 2 * 6$ & 12 & 15 & 30 & 30 & 0.18 & $0.41(0.194-0.865)$ \\
\hline$N A T 2 * 4 / N A T 2 * 7$ & 0 & 0 & 1 & 1 & 0.909 & - \\
\hline Total & 36 & 45 & 47 & 47 & 0.791 & $0.92(0.51-1.66)$ \\
\hline \multicolumn{7}{|l|}{ Slow acetylator } \\
\hline$N A T 2 * 5 / N A T 2 * 5$ & 11 & 13.8 & 14 & 14 & 0.964 & $0.98(0.42-2.286)$ \\
\hline$N A T 2 * 5 / N A T 2 * 6$ & 16 & 20 & 25 & 25 & 0.427 & $0.75(0.146-3.838)$ \\
\hline$N A T 2 * 5 / N A T 2 * 7$ & 3 & 3.8 & 1 & 1 & 0.462 & $3.86(0.394-37.77)$ \\
\hline$N A T 2 * 6 / N A T 2 * 6$ & 8 & 10 & 12 & 12 & 0.671 & $0.81(0.317-2.073)$ \\
\hline$N A T 2 * 6 / N A T 2 * 7$ & 2 & 2.5 & 1 & 1 & 0.896 & $2.53(0.225-28.162)$ \\
\hline$N A T 2 * 7 / N A T 2 * 7$ & 4 & 2.5 & 0 & 0 & 0.079 & - \\
\hline Total & 44 & 47 & 53 & 53 & 0.791 & $1.08(0.597-1.952)$ \\
\hline
\end{tabular}

$(\mathrm{OR}=5.25)$; however, in this case no statistical significance was shown.

three times higher in patients with $N A T 2 * 5 / N A T 2 * 7$ genotype $(\mathrm{OR}=3.86)$ and two times higher in subjects with $N A T 2 * 6 / N A T 2 * 7$ genotypes $(\mathrm{OR}=2.53)$ than in patients with the other genotypes. However, no statistical significance was reported in other cases. In addition there were no differences between the control group and patients with either UC or CD to the distribution of NAT2 genotypes (Tables 3 and 4).

On the basis of the obtained results of genotyping, incidence of particular alleles in the patients with IBD and in the control group was assessed (Table 5). Allele NAT2*5 was predominant in the subjects with IBD (36.2\%), whereas $N A T 2 * 6$ allele prevailed in the control group (40\%). Relative risk of the occurrence of the IBD, expressed by the odds ratio, was almost six times higher in the subjects with $N A T 2 * 7$ allele $(\mathrm{OR}=5.8)$. This correlation was statistically significant $(P=0.005)$. Such correlation was not observed in patients carrying other alleles of the NAT2 gene. Relative risk of occurrence of the CD was five-fold higher in patients with the NAT2*7 allele

\section{Discussion}

The human organism is continuously exposed to noxious external agents (xenobiotics), including drugs and carcinogenic compounds which may cause numerous diseases. Xenobiotic metabolizing enzymes, present in the human body, are the first-line defense against environmental agents. The processes of biotransformation in the organism are multidirectional and xenobiotics can be transformed into active or inactive metabolites via an oxidative pathway. They can also be transformed into harmful compounds with a potentially pathogenic action [21]. Many xenobiotic metabolizing enzymes, such as the P-450 cytochrome group, glutathione transferase or $\mathrm{N}$-acetyltransferase, show genetic polymorphism, which contributes to marked differences in drug metabolism among individuals. There are numerous reports demonstrating the role of acetylation 
Table 3 Frequency

distributions of NAT2 genotypes in the group of patients with UC and in the controls
$U C$ ulcerative colitis, $O R$ odds ratio, $95 \%$ CI $95 \%$ confidence interval

$P$ significantly lower $(P<0.01)$

\section{Table 4 Frequency} distributions of NAT2 genotypes in the group of patients with $\mathrm{CD}$ and in the controls
$C D$ Crohn's disease, $O R$ odds ratio, $95 \%$ CI $95 \%$ confidence interval

$P$ significantly lower $(P<0.01)$

\begin{tabular}{|c|c|c|c|c|c|c|}
\hline \multirow[t]{2}{*}{ NAT2 genotype } & \multicolumn{2}{|c|}{ Patients with UC, $N=53$} & \multicolumn{2}{|c|}{ Controls, $N=100$} & \multirow[t]{2}{*}{$P$} & \multirow[t]{2}{*}{ OR $(95 \% \mathrm{CI})$} \\
\hline & $n$ & $\%$ & $n$ & $\%$ & & \\
\hline \multicolumn{7}{|l|}{ Fast acetylator } \\
\hline \multicolumn{7}{|l|}{ Homozygous } \\
\hline$N A T 2 * 4 / N A T 2 * 4$ & 7 & 13.2 & 4 & 4 & 0.036 & $3.6(0.769-16.827)$ \\
\hline \multicolumn{7}{|l|}{ Heterozygous } \\
\hline$N A T 2 * 4 / N A T 2 * 5$ & 11 & 20.8 & 12 & 12 & 0.149 & $1.92(0.785-4.692)$ \\
\hline$N A T 2 * 4 / N A T 2 * 6$ & 6 & 11.3 & 30 & 30 & 0.01 & $0.3(0.117-0.771)$ \\
\hline$N A T 2 * 4 / N A T 2 * 7$ & 0 & 0 & 1 & 1 & 0.507 & - \\
\hline Total & 24 & 45.3 & 47 & 47 & 0.839 & $0.93(0.477-1.813)$ \\
\hline \multicolumn{7}{|l|}{ Slow acetylator } \\
\hline$N A T 2 * 5 / N A T 2 * 5$ & 6 & 11.3 & 14 & 14 & 0.639 & $0.78(0.281-2.166)$ \\
\hline$N A T 2 * 5 / N A T 2 * 6$ & 12 & 22.6 & 25 & 25 & 0.74 & $0.88(0.402-1.927)$ \\
\hline$N A T 2 * 5 / N A T 2 * 7$ & 1 & 1.9 & 1 & 1 & 0.017 & $1.9(0.117-30.969)$ \\
\hline$N A T 2 * 6 / N A T 2 * 6$ & 6 & 11.3 & 12 & 12 & 0.887 & $0.94(0.332-1.523)$ \\
\hline$N A T 2 * 6 / N A T 2 * 7$ & 1 & 1.9 & 1 & 1 & 0.017 & $1.9(0.117-30.969)$ \\
\hline$A T 2 * 7 / N A T 2 * 7$ & 3 & 5.7 & 0 & 0 & 0.09 & - \\
\hline Total & 29 & 54.7 & 53 & 53 & 0.839 & 1.07 (0.549-2.088) \\
\hline
\end{tabular}

\begin{tabular}{|c|c|c|c|c|}
\hline \multirow[t]{2}{*}{ NAT2 genotype } & Patients with $\mathrm{CD}, N=27$ & Controls, $N=100$ & \multirow[t]{2}{*}{$P$} & \multirow[t]{2}{*}{ OR $(95 \% \mathrm{CI})$} \\
\hline & $\%$ & $\%$ & & \\
\hline
\end{tabular}

\begin{tabular}{|c|c|c|c|c|c|c|}
\hline \multicolumn{7}{|l|}{ Fast acetylator } \\
\hline \multicolumn{7}{|l|}{ Homozygous } \\
\hline$N A T 2 * 4 / N A T 2 * 4$ & 0 & 0 & 4 & 4 & 0.633 & - \\
\hline \multicolumn{7}{|l|}{ Heterozygous } \\
\hline$N A T 2 * 4 / N A T 2 * 5$ & 6 & 22.2 & 12 & 12 & 0.3 & $2.09(0.703-6.214)$ \\
\hline$N A T 2 * 4 / N A T 2 * 6$ & 6 & 22.2 & 30 & 30 & 0.58 & $0.67(0.246-1.829)$ \\
\hline$N A T 2 * 4 / N A T 2 * 7$ & 0 & 0 & 1 & 1 & 0.08 & - \\
\hline Total & 12 & 44.4 & 47 & 47 & 0.806 & $0.9(0.382-2.102)$ \\
\hline \multicolumn{7}{|l|}{ Slow acetylator } \\
\hline$N A T 2 * 5 / N A T 2 * 5$ & 5 & 18.5 & 14 & 14 & 0.777 & $1.4(0.455-4.302)$ \\
\hline$N A T 2 * 5 / N A T 2 * 6$ & 5 & 18.5 & 25 & 25 & 0.655 & $0.68(0.233-1.982)$ \\
\hline$N A T 2 * 5 / N A T 2 * 7$ & 2 & 7.4 & 1 & 1 & 0.218 & $7.92(0.69-90.63)$ \\
\hline$N A T 2 * 6 / N A T 2 * 6$ & 2 & 7.4 & 12 & 12 & 0.729 & $0.59(0.124-2.807)$ \\
\hline$N A T 2 * 6 / N A T 2 * 7$ & 0 & 0 & 1 & 1 & 0.909 & - \\
\hline$N A T 2 * 7 / N A T 2 * 7$ & 1 & 3.7 & 0 & 0 & 0.484 & - \\
\hline Total & 15 & 55.6 & 53 & 53 & 0.806 & $1.11(0.473-2.604)$ \\
\hline
\end{tabular}

polymorphism in predisposing towards development of neoplasm's, allergies and neurological diseases [22-31].

$\mathrm{N}$-acetylation reaction plays a crucial role in the detoxification of carcinogenic arylamines in the human body. Both drugs and known environmental carcinogens are subjected to acetylation. Throughout this process hydrophobic compounds are converted into hydrophilic ones and subsequently can be removed by kidneys or in bile $[32,33]$.
$\mathrm{N}$-Aminotransferases 1 and 2 Catalyze the NAcetylation Reaction

Inflammatory bowel disease is becoming a more and more serious social problem since incidence of the disease is still growing along with the advancement of our civilization [34, 35]. Patients with IBD may be also at higher risk of development of colorectal cancer. According to some reports individuals with IBD develop colorectal cancer six times 


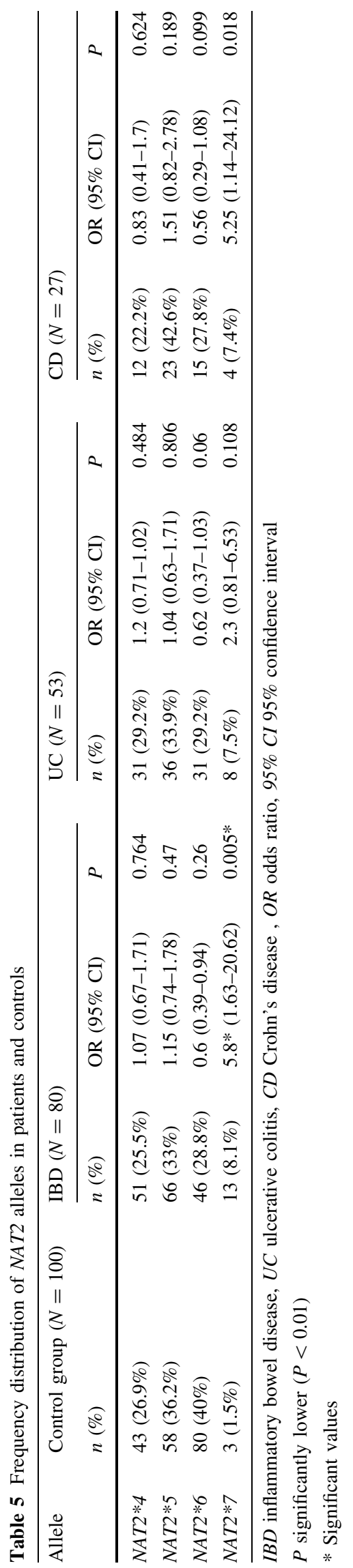

more frequently than healthy people [36, 37]. However, other results of different studies suggest that IBD led to the development of neoplasms only in $0.5-2 \%$ of cases [38-40].

Research on the correlations of the acetylation rate with development of IBD is also vital because etiology and pathogenesis of the disease is still unclear despite many long-term studies. Genetic determination is believed to play a role. Numerous studies on the genetic basis of inflammatory bowel disease revealed correlations with certain chromosomal changes [4, 5, 41]. A clear correlation between Crohn's disease and mutations was revealed in the following genes: NOD2/CARD15 (nucleotide-binding oligomerization domain 2) gene, also known as (caspase recruitment domain 15 gene); ATG16L1 (autophagy related 16-like protein); NKX2-3 (NK2 transcription factor related, locus 3); and in the IL-23 receptor-encoding gene (IL23R) $[1,4,37]$. Relation between genetic predisposition to the development of IBD and some HLA class II antigens (B27, B52, DR2, DR3, DR9, DQ2) was reported [4, 5]. However, in the literature there are rare and sometimes conflicting data on the influence of acetylation polymorphism on the development of the IBD [41-43].

The aim of our study was to investigate the relation between genetically determined rate of acetylation process and the risk of developing of inflammatory bowel disease in a Polish population.

Knowledge of this dependence could be helpful in the explanation of the etiology and pathogenesis of the disease and may allow us to detect newer predisposing factors.

In our study we observed a slightly higher proportion of slow acetylators in the group of patients with IBD than in the group of healthy subjects. It was shown that the frequency of genotypes for the poor and fast acetylation in the group of patients with IBD reached 55 and $45 \%$, respectively, compared with 53\% for slow and $47 \%$ for fast acetylation in the control group. No statistically significant differences in the incidence of NAT2 genotypes for slow and fast acetylation between the studied groups were found $(P=0.578)$. These results were in accordance with the distribution of acetylation genotypes observed in the Caucasian population $[44,45]$.

Patients with IBD more frequently had NAT2*4/NAT2*5 $(21.3 \%)$ and $N A T 2 * 5 / N A T 2 * 6(20 \%)$ genotypes. NAT2*4/ $N A T 2 * 6(30 \%)$ and $N A T 2 * 5 / N A T 2 * 6(25 \%)$ genotypes were predominant in the control group. No statistically significant difference between frequency of particular NAT2 genotypes in the group of subjects with IBD and in the control group was observed. Relative risk of development of IBD was three-fold higher for the carriers of $N A T 2 * 5 / N A T 2 * 7$ allele $(\mathrm{OR}=3.86)$ and two-times higher for the subjects with $N A T 2 * 6 / N A T 2 * 7$ allele $(\mathrm{OR}=2.53)$ in comparison to the carriers of other alleles; however, in both cases no statistical significance was showed. 
Available literature provides ambiguous results of the studies on the relations between acetylation polymorphism and the development of the IBD. Mahid et al. assessed genetic polymorphism of the NAT1 and NAT2 enzymes in the subjects with colorectal cancer and with IBD. No statistically significant difference between frequency of particular polymorphic alleles and the increased risk of development of bowel diseases was reported [42]. On the other hand, studies performed by Machida et al. revealed that the $N A T 2 * 7 B$ allele, which determines slow acetylation, is related to Crohn's disease in the Japanese population $(\mathrm{OR}=2.8 ; P=0.013)$ [41].

Results of our study showed that relative risk of development of IBD, which was expressed by the odds ratio, was almost six times higher in $N A T 2 * 7$ allele carriers $(\mathrm{OR}=5.8)$. The correlation was statistically significant $(P=0.005)$. No such correlation was found in the case of patients with other alleles of the NAT2 gene. Relative risk of occurrence of the $\mathrm{CD}$ was five-fold higher in patients with $N A T 2 * 7$ allele $(\mathrm{OR}=5.25)$; however, in this case no statistical significance was shown.

Therefore, it can be assumed that polymorphism of the NAT2 enzyme is one of the agents predisposing to the development of the disease.

There are far more reports on the role of NAT2 polymorphism in the development of neoplasms [46-49]. Gastrointestinal cancers such as gastric, duodenal, colorectal and pancreatic cancers are among the most frequent malignant tumors. Colorectal cancer is the most prevalent tumor and the second most lethal among all neoplasm's that occur in the Polish population [50]. NAT2 metabolizes carcinogenic compounds: heterocyclic aromatic amines and polycyclic aromatic hydrocarbons, which are produced in the course of meat processing such as grilling or frying. Both smoking and eating fried meat may lead to the development of this tumor. Lila et al. reported that the NAT1 and NAT2 fast genotypes may contribute jointly to individual susceptibility and may play an important role in colorectal cancer associated with red meat and possibly also exposure to environmental tobacco smoke [25]. However, according to Kiyohra et al., the relation between NAT2 polymorphism and colorectal cancer is rather insignificant. On the other hand, there is still correlation between development of colorectal cancer, meat consumption, fast acetylation by NAT2 and high activity of CYP1A2. Coexistence of the NAT2 genotype, determining fat acetylation and CYP1A2, responsible for fast $\mathrm{N}$-hydroxylation, increase the risk of carcinoma in people eating fried meat $(\mathrm{OR}=2.8)$ [22].

Apart from the potential influence on the development of certain diseases, genetically determined acetylation polymorphism may also affect pharmacokinetic reactions of several drugs. In some patients, especially in the case of chronic treatment, therapeutic effects may be either increased or decreased or interactions between medicines and hazardous side effects may occur [51]. N-acetyltransferase metabolizes a number of commonly used drugs, such as sulphasalazine, used in patients with rheumatoid arthritis and inflammatory bowel diseases. Kumagal et al. studied the effectiveness of the drug depending on the NAT2 genotype. It was shown that, depending on the NAT2 genotype, a proportion of sulphapiridine (an active component of the sulphasalazine) in its acetylated form was found to be different. This difference in the proportion of the drug and its metabolite is the evidence of different efficacy of the sulphasalazine in patients with different genotypes [23].

Sulphasalazine is frequently used in the treatment of inflammatory bowel disease. Chen et al. studied NAT2 polymorphism and its correlation with the side effects of sulphasalzine in patients with IBD. It was revealed that patients with IBD who were characterized by the slow acetylation genotype without the wild-type $N A T 2 * 4$ allele experienced side effects of the drug more frequently (36\%) than individuals with fast acetylation genotype, including at least 1 wild-type $N A T 2 * 4$ allele $(11 \%)$, but the results were found to be not statistically significant [52].

Knowledge of genetically determined individual differences in the xenobiotic metabolism is an important clinical problem considering both individual pharmacotherapy and relations between the acetylation genotype and the risk of development of diseases with an unknown etiology, including inflammatory bowel disease.

Acknowledgments This work was supported by grant No. 503-8011-1 from the Medical University of Lodz, Poland.

Open Access This article is distributed under the terms of the Creative Commons Attribution Noncommercial License which permits any noncommercial use, distribution, and reproduction in any medium, provided the original author(s) and source are credited.

\section{References}

1. Cho JH, Abraham C. Inflammatory bowel disease genetics: NOD2. Annu Rev Med. 2007;58:401-416.

2. Dotan I, Mayer L. Immunopathology of inflammatory bowel disease. Curr Opin Gastroenterol. 2002;18:416-427.

3. Shergill AK, Terdiman JP. Controversies in the treatment of Crohn's disease: the case for an accelerated step-up treatment approach. World J Gastroenterol. 2008;14:2670-2677.

4. Cho J, Weaver C. The genetics of inflammatory bowel disease. Gastroenterology. 2007;133:1327-1339.

5. Stokkers PFC, Reitsma PH, Tytgat NJ, van Deventer SJH. HLADR and-DQ phenotypes in inflammatory bowel disease: a metaanalysis. Gut. 1999;45:395-401.

6. Pompeo F, Brooke E, Kawamura A, Mushtaq A, Sim E. The pharmacogenetics of NAT: structural aspects. Pharmacogenomics. 2002;3:19-30. 
7. Ladero JM. Influence of polymorphic N-acetylotransferase on non-malignant spontaneous disorders and on response to drugs. Curr Drug Metab. 2008;9:532-537.

8. Rovito P, Morse P, Spinek K, et al. Heterocyclic amines and genotype of $\mathrm{N}$-acetyltransferases as risk factors for prostate cancer. Prostate Cancer Prostatic Dis. 2005;8:69-74.

9. University of Louisville. Human NAT2 alleles (Haplotypes). University of Louisville, Department of Pharmacology and Toxicology. 2010. http://louisville.edu/medschool/pharmacology. Accessed 04 February 2011.

10. Hein DW, Doll M, Fretland A. Molecular genetics and epidemiology of the NAT1 and NAT2 acetylation polymorphisms. Cancer Epidemiol Biomark Prev. 2000;9:29-42.

11. Weizmann Institute of Science. The GeneCards human gene database. $\mathrm{N}$-acetyltransferase 2 (arylamine $\mathrm{N}$-acetyltransferase). 2010. http://www.genecards.org/cgi-bin/carddisp.pl?gene=NAT2. Accessed 04 February 2011.

12. Cascorbi N, Drakoulis J, Brockmoller A, Maurer K, Sperling K. Arylamine N-acetyltransferase (NAT2) mutations and their allelic linkage in unrelated Caucasian individuals: correlation with phenotypic activity. Am J Hum Genet. 1995;57:581-592.

13. McKay J, Hashibe M, Hung RJ. Sequence variations of NAT1 and NAT2 and other xenometabolic genes and risk of lung and aerodigestive tract cancer in central Europe. Cancer Epidemiol Biomarkers Prev. 2008;17:141-147.

14. García-Closas M, Malats N, Silverman D, Dosemeci M, Kogevinas M. NAT2 slow acetylation, GSTM1 null genotype, and risk of bladder cancer: results from the Spanish bladder cancer study and meta-analyses. Lancet. 2005;366:649-659.

15. Cooper GS. N-acetyltransferase genotypes in relation to risk of developing systemic lupus erythematosus. J Rheumatol. 2004;31(1): 76-80.

16. Borlak J, Reamon-Buettner SM. N-acetyltransferase 2 (NAT2) gene polymorphisms in Parkinson's disease. BMC Med Genet. 2006;7:58.

17. Rocha L, Garcia C, de Mendonça A. N-acetyltransferase (NAT2) genotype and susceptibility of sporadic Alzheimer's disease. Pharmacogenetics. 1999;9:9-15.

18. Batra J, Ghosh B. N-acetylotransferases as markers for asthma and allergic/atopic disorder. Curr Drug Metab. 2008;9:546-553.

19. Gustincich S, Manfioletti G, Del Sal G, Schneider C, Carninci P. A fast method for high-quality genomic DNA extraction from whole human blood. Biotechniques. 1991;1(3):298-300.

20. Spurr NK, Gough AC. Polymorphisms in drug-metabolizing enzymes as modifiers of cancer risk. Clin Chem. 1995;41: $1864-1869$.

21. Lemos MC, Cabrita FJ, Silva HA, Vivan M, Placido F, Regateiro FJ. Genetic polymorphism of CYP2D6, GSTM1 and NAT2 and susceptibility to haematological neoplasias. Carcinogenesis. 1999;20:1125-1129.

22. Kiyohara C. Genetic polymorphism of enzymes involved in xenobiotic metabolism and the risk of colorectal cancer. $J$ Epidemiol. 2000;10:349-360.

23. Kumagal S, Komada F, Kita T, Morinobu A. N-acetylotransferase 2 genotype-related efficacy of sulfasalazine in patients with rheumatoid arthritis. Pharmacol Res. 2004;21:324-329.

24. Lei D, Pan X, Guo C, Xu F. Relationship between polymorphism of $\mathrm{N}$-acetyltransferase 2 and genetic susceptibility to laryngeal carcinoma. Zhonghua Zhong Liu Za Zhi. 2002;24:154-156.

25. Lilla C, Verla-Tebit E, Risch A, Jager B, Hoffmeister M. Effect of NAT1 and NAT2 genetic polymorphism on colorectal cancer risk associated with exposure to tabacco smoke and meat consumption. Cancer Epidemiol Biomarkers Prev. 2006;15:99-107.

26. Luszawska-Kutrzeba T. NAT2 genotype in children with bronchial asthma and other atopic diseases. Probl Ter Monitor. 1998;9:115-122.
27. Niewiński P, Orzechowska-Juzwenko K. Importance of genetically determined acetylation of drugs and xenobiotics in pathogenesis of neoplasmatic diseases. Pol Merk Lek. 1997;2:231-235.

28. Pawlik A, Ostanek L, Brzosko I, Gawroska-Szklarz B. Increased genotype frequency of $\mathrm{N}$-acetyltransferase 2 slow acetylation in patients with rheumatoid arthritis. Clin Pharmacol Ther. 2002; $72: 319-325$.

29. Skrętkowicz K, Skrętkowicz J, Gawrońska-Szklarz B, Górnik W, Rychlik-Sych M, Sysa-Jędrzejowska A. Lack of association between arylamine $\mathrm{N}$-acetylotransferase polymorphism and systemic sclerosis. Eur J Clin Parmacol. 2005;60:773-778.

30. Varzim G, Monteiro E, Silva R, Pinheiro C, Lopes C. Polymporphism of arylamince N-acetylotransferase (NAT1 and NAT2) and larynx cancer susceptibility. ORL (J Rhino-Laryngology). 2002;64:206-212.

31. Zhou W, Liu G, Thurston SW. Genetic polymorphisms in $\mathrm{N}$-acetyltransferase-2 and microsomal epoxide hydrolase, cumulative cigarette smoking and lung cancer. Cancer Epidemiol Biomarkers Prev. 2002;11:15-21.

32. Rychlik-Sych M, Skrętkowicz J. Drug metabolism. Farm Pol. 2008;64:51-60.

33. Dyderski S, Grzymisławski M. Metabolism of drugs, 1. Basic metabolic reaction. Pol Merk Lek. 2005;106:446-452.

34. McFarland LV. State-of-the-art of irritable bowel syndrome and inflammatory bowel disease research in 2008. World Gastroenterol. 2008;14:2625-2629.

35. Scaldaferri F, Fiocchi C. Inflammatory bowel disease: progress and current concepts of etiopathogenesis. J Digest Dis. 2007;8:171-178.

36. Itzkowitz $\mathrm{SH}$, Yio X. Inflammation and cancer IV. Colorectal cancer in inflammatory bowel disease: the role of inflammation. Am J Physiol Gastrointest Liver Physiol. 2004;287:G7-G17.

37. Ekbom A, Helmick C, Zack M, Adami HO. Ulcerative colitis and colorectal cancer. A population-based study. $N$ Engl J Med. 1990;323:1228-1233.

38. Choi PM, Zelig MP. Similarity of colorectal cancer in Crohn's disease and ulcerative colitis: implications for carcinogenesis and prevention. Gut. 1994;35:950-954.

39. Jess T, Loftus EV Jr, Velayos FS, et al. Risk of intestinal cancer in inflammatory bowel disease: a population-based study from Olmsted county, Minnesota. Gastroenterology. 2006;130:1039-1046.

40. Herszenyi L, Miheller P, Tulassay Z. Carcinogenesis in inflammatory bowel disease. Dig Dis. 2007;25:267-269.

41. Machida H, Tsukamoto K, Wen C, Shikuwa S. Crohn's disease in Japanese is associated with a SNP-haplotype of N-acetylotransferase 2 gene. World J Gastroenterol. 2005;11:4822-4837.

42. Mahid SS, Colliver DW, Crawford N. Characterization of $\mathrm{N}$-acetyltansferase 1 and 2 polymorphism and haplotype analysis for inflammatory bowel disease and sporadic colorectal carcinoma. BMC Med Genet. 2007;8:28-34.

43. de Jong DJ, van der Logt EMJ, van Schaik A. Genetic polymorphisms in biotransformation enzymes in Crohn's disease: association with microsomal epoxide hydrolase. Gut. 2003;52: $547-551$

44. Hickman D, Sim E. N-acetyltransferase polymorphism composition of phenotype and genotype in humans. Biochem Pharmacol. 1991;42:1007.

45. Lin HJ, Han CY, Lin BK, et al. Ethic distribution of slow acetylator mutations in the polymorphic N-acetyltransferase (NAT2) gene. Pharmacogenetics. 1999;4:125-134.

46. Golka K, Prior V, Błaszkewicz M, Bolt HM. The enhanced bladder cancer susceptibility of NAT2 slow acetylators towards aromatic amines: a review considering ethnic differences. Toxicol Lett. 2002;128:229-241.

47. Gu J, Liang D, Wang Y, Lu C, Wu X. Effects of N-acetyltransferase 1 and 2 polymorphisms on bladder cancer risk in Caucasians. Mutat Res. 2005;581:97-104. 
48. Ochs-Balcom HM, Wiesner G, Elston RC. A meta-analysis of the association of $\mathrm{N}$-acetyltransferase 2 gene (NAT2) variants with breast cancer. Am J Epidemiol. 2007;166:246-254.

49. Schnakenberg E, Ehlers C. Genotyping of the polymorphic $\mathrm{N}$-acetyltransferase (NAT2) and loss of heterozygosity in bladder cancer patient. Clin Genet. 1998;53:396-402.

50. Barańska M, Skrętkowicz J. Genetic polymorphism of oxidation and acetylation in cancers of digestive system. Pol Merk Lek. 2009;152:145-147.
51. Gawrońska-Szklarz B. Influence of genetic factors on drug treatment efficacy and safety in cardiovascular diseases. Acta Angiol. 2003;9:1-15.

52. Chen M, Xia B, Guo Q, Li J, Ye M, Hu Z. N-acetyltransferase 2 slow acetylators genotype associated with adverse effects of sulphalazine in the treatment of inflammatory bowel disease. Can J Gastroenterol. 2007;21:155-158. 